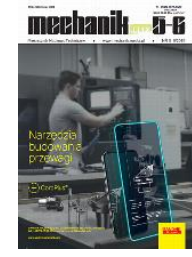

How to cite this article:

Author: Adam Ruszaj

Title of article: "Additive methods in micro and nano manufacturing technologies"

Mechanik, No. 5-6 (2019)

DOI: https://doi.org/10.17814/mechanik.2019.5-6.43

\title{
Additive methods in micro and nano manufacturing technologies
}

ADAM RUSZAJ *

Prof. dr hab. inż. Adam Ruszaj, ruszaj@mech.pk.edu.pl, aruszaj@pwsz-ns.edu.pl, https://orcid.org/0000-0002-1809-3271 - Wydział Mechaniczny Politechniki Krakowskiej oraz Instytut Techniczny PWSZ w Nowym Sączu

In 1959 R.P. Feynman has presented the concept and strategy of micro - and nanotechnology development. Their introduction to the practice took place after working out the scanning tunneling microscopy (1981) and atomic force microscopy (1985). In the further development of micro- and nanotechnology the micro and nano electromechanical systems (MEMS, NEMS) have been worked out. MEMS and NEMS are widely applied in majority of modern equipment and their production increases about $17 \div 20 \%$ per year since 1990 s. MEMS and NEMS manufacture usually is a difficult technological problem because of small dimensions and complex outside and inside structures. In such cases the application of additive manufacturing processes can be very promising. In the paper the possibilities of additive manufacturing processes applications, mainly in microtechnologies, is presented.

KEYWORDS: additive manufacturing, microtechnologies, nanotechnologies, MEMS, NEMS

\section{Introduction}

On December 29, 1959, at the California Institute of Technology, an American physicist, later a Nobel Prize winner (1965), Richard P. Feynman (1918-1988) at the annual meeting of the Association of American Physicists gave a lecture, "There is a plenty room at the bottom" [1]. He presented in it, among others, technological vision of additive building of nanoelements (atom by atom or particle by particle) - bottom up, or "extreme downward miniaturization" - top down.

Further development of micro - and nanotechnology resulted in the development, application and dynamic improvements of micro- and nanoelectromechanical systems (MEMS, NEMS). Their production has been growing since the 1990 s by approximately $17 \div 20 \%$ per year. The production of nano- and microelements found in these systems (especially in the actuators) an important, but at the same time a very technologically difficult task.

Parallel to micro- and nanotechnologies, bionics, i.e. science studying processes, structures and materials occurring in the Nature, is developing in order to significantly improve the design solutions of machine and device elements. The introduction of bionic changes in elements usually significantly impedes their manufacturing by traditional removal ethods or forming methods. Such complex bionic structures can be efficiently produced by additive methods.

The term "bionics" was first used at the conference "Living prototypes of artificial organs", which took place in Dayton in 1960, i.e. less than a year after the publication of the concept of R.P. Feynman. In other words, dynamic parallel development of micro- and nanotechnology and bionic has been observed since the 1960s. On the basis of publications in this field, these terms can be defined in the field of production engineering [1-4].

Nanotechnology is the ability to build nanoelements and nanomaterials from single atoms, particles and sets of particles, and to integrate manufactured nanoelements or nanostructures into larger systems: micro-, meso- and macro-systems.

In production engineering, nanotechnology includes the production and use of elements at least with one dimension in the range of $0.1 \div 100 \mathrm{~nm}(1 \mathrm{D})$, as well as their integration into larger systems: micro-, meso- and macro systems. 
Microtechnology is the ability to produce micro-elements with at least one dimension in the range of $0.1 \div 1000 \mu \mathrm{m}(1 \mathrm{D})$, and their integration into larger systems: meso- and macro systems.

Technological concepts formulated by R.P. Feynman - bottom up and top down - is illustrated in fig. 1.

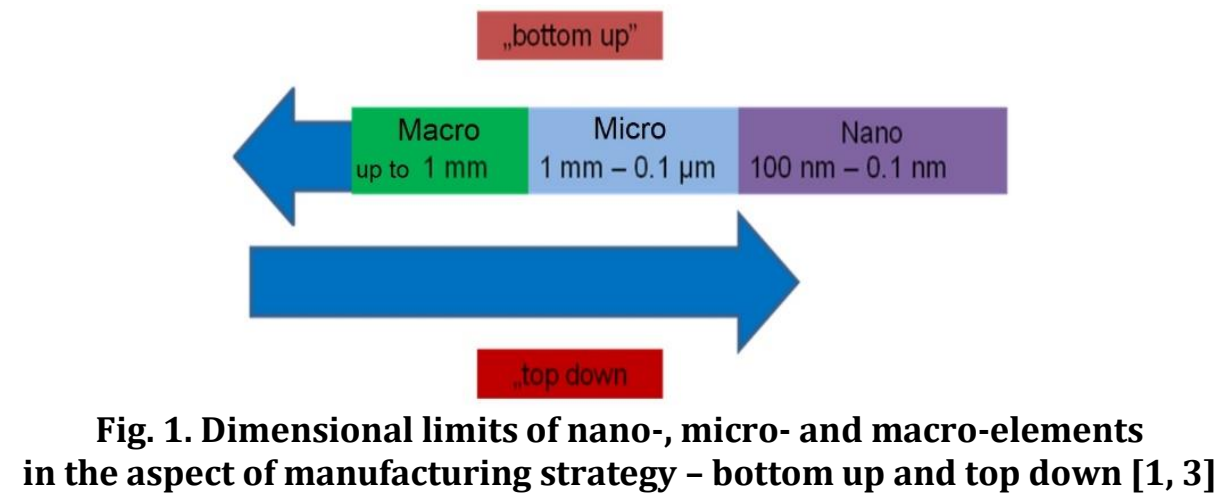

As mentioned, due to the implementation of the R.P. Feynman's concept Scanning Tunnel Microscope (1981) and Atomic Force Microscope (1985) were built at the IBM Research Laboratory in Zurich. In the case of electrically conductive materials, a modern Scanning Tunneling Microscope (STM) allows:

- imaging of the atomic structure and scanned surface profile with a minimum resolution of $0.1 \div 0.2 \mathrm{~nm}$,

- "building" the structures from individual atoms - sufficiently high voltage applied to the tunnel microscope probe pulls the atom from the sample surface and allows it to be placed anywhere.

A modern atomic force microscope (AFM) from Digital Instruments (USA) allows imaging of the atomic structure and profile (outline) of the scanned surface of electrically conductive and non-conductive materials with a resolution of $0.1 \div 10 \mathrm{~nm}$.

The use of STM and AFM microscopes has intensified the development of manufacturing micro- and nanotechnology, and one of its important directions is the improvement of micro- and nanoelectromechanical systems (MEMS and NEMS).

The structure of these systems is shown in fig. 2. The basic elements of MEMS and NEMS are sensors that identify the state of the process/object, and actuators that physically control the process/object. Actuator components are manufactured using nano- and microtechnology; in the simplest case, the basic elements are microor nanoelements (e.g. holes, cylinders, sleeves, gears and gears).

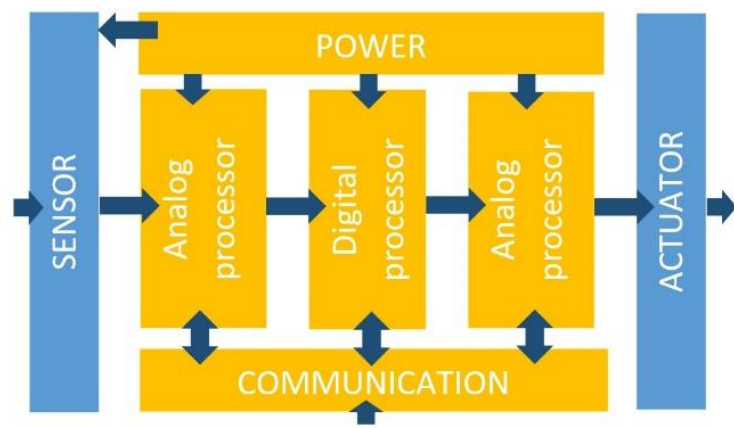

Fig. 2. Block diagram of MEMS and NEMS systems [3]

Due to the extensiveness of the issue, the paper characterizes primarily the possibilities of applying additive methods in microtechnologies.

\section{Characteristics of microelement production methods}

Microelements - i.e. objects one (1D), two (2D) or three (3D) dimensions which are in the range from 100 $\mathrm{nm}$ to $1 \mathrm{~mm}$ - are used in many devices, but most are written about their use in MEMS actuators. In the production of microelements, both removal and additive methods are used, as well as methods, in which the volume or mass of the element does not change, but gives it the right shape. Due to the ever-growing MEMS market 
$(\sim 17 \div 20 \%$ per annum), it is necessary to develop rational mass production technologies. Moulding processes, i.e. plastic forming, and microelement moulding under pressure, mainly from plastics (injection molding) are of great importance here. Currently, many removal processes are also used that use various phenomena to shape microelements, including:

- mechanical impact of tools such as drills, milling cutters, stamping dies, matrices or water-abrasive stream: machining, plastic forming; in all these cases, the limitation of the shapes and dimensions of produced microparts and microstructures are mechanical forces occurring in the process; these forces result from the properties of the workpiece and must be selected so as not to damage the workpiece or tool [5-7];

- melting and evaporation or ablation: electro-discharge (EDM), laser (LBM) or electron (EBM) treatment; in these methods, the processed material is removed as a result of melting and evaporation, and in the case of treatment with femtosecond laser pulses - even ablation, i.e. the transition of the material directly from the solid state to the gas state [7-9];

- electrochemical dissolution: electrochemical machining (ECM) [10, 11]; in electrochemical machining, the material is removed in the smallest portions, atom by atom; therefore, with optimally selected machining conditions, very good surface properties of the metal or steel being processed can be obtained; due to the lack of mechanical forces acting on the workpiece and the tool, the process is widely used in micro- and nano-machining.

In forming methods - that is, giving shape without changing the mass and volume - an important role, especially in mass production, play (apart from plastic working) the processes of casting and injection moulding [7, 12 , 13]. In micro-casting and micro-injection moulding (microinjection moulding) the biggest problem is the production of microforms. In plastic working, the shape of the material is obtained as a result of mechanical impact on the material such tools as stamping dies or matrices. In all cases of plastic forming, achieving the desired shapes and dimensions of manufactured elements, especially microelements or microstructures, limit the mechanical forces occurring in the process. These forces result from the properties of the workpiece and must be selected so as not to damage the workpiece or tool [5-7].

Additive manufacturing processes give the greatest possibilities of producing microelements with a complex shape and complex internal structure. Therefore, in the further part of the paper selected additive manufacturing processes are characterized in terms of manufacturing microtechnology.

\section{Selected micro-technologies of additive manufacturing}

Additive methods - due to the specificity of building elements - are the most universal and are most suitable for producing sophisticated shapes or structures. Particularly valuable are the possibilities of making thinwalled elements with a complex internal structure. Restrictions result primarily from the type of starting material and the specificity of the material adding processes, such as: cutting and bonding (gluing, soldering or even welding), photolithography, sintering and melting of powders of any materials or extrusion of plasticized material (plastic).

The analysis of the additive manufacturing processes used in production in the aspect of the proposed definitions leads to the conclusion that they are micro-technologies (adding 1D, 2D and 3D microelements), and in the case of two-photon polymerization process (2pp) the limit of nanotechnology has been achieved, because the portions of the added material have dimensions even $100 \div 200 \mathrm{~nm}$. From this, it follows that 2pp polymerization is another stage in the development of the stereolithography process.

A good example of the possibilities of current additive manufacturing processes is the Mobius band model shown in fig. 3 [14-17].

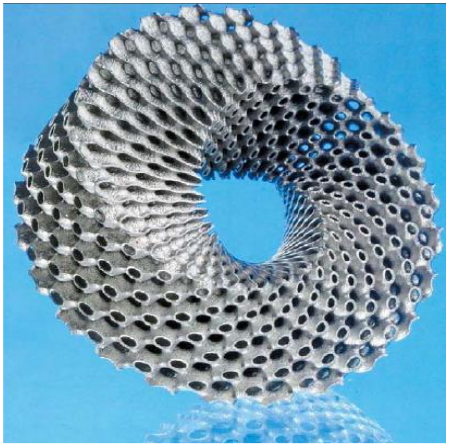

Fig. 3. Mobius-shaped element made using the SLM method on the SLM realizer 250 by MCP-HEK Tooling [14] 


\section{Laminated object manufacturing (LOM)}

LOM consists in manufacturing elements by cutting successive layers of paper, metal foil, plastic foil, fabrics, etc. and bonding them (gluing, welding, soldering, etc.). Their thickness usually varies from several dozen to several hundred micrometers [15-17].

The LOM process is widely used in:

- visualization of designed objects for the initial assessment of their functionality or aesthetics (including in architecture, machinery and automotive industry),

- manufacturing cores for foundry processes (from paper, plastics) - in casting by the fired model method,

- manufacture of forming tools from foil or metal sheets, eg foundry molds, stamping dies for the production of car bodies and injection molds (e.g. at Toyota).

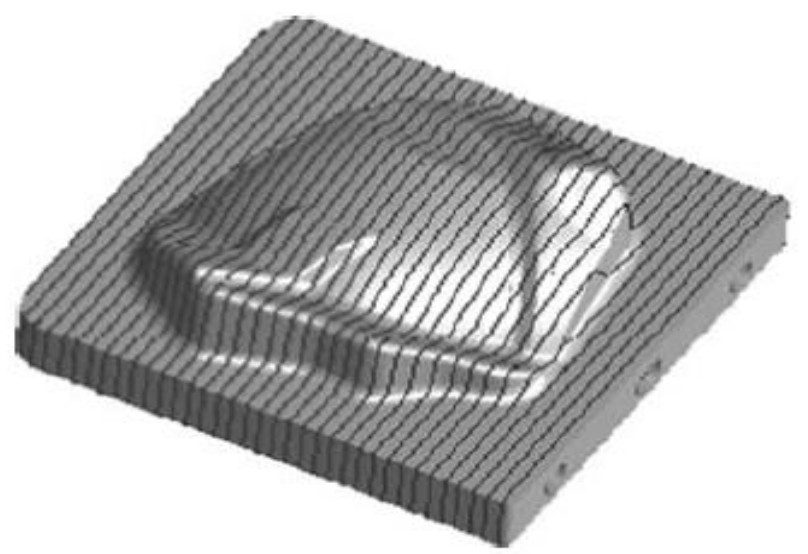

Fig. 4. Shaped tool made using the LOM method [16]

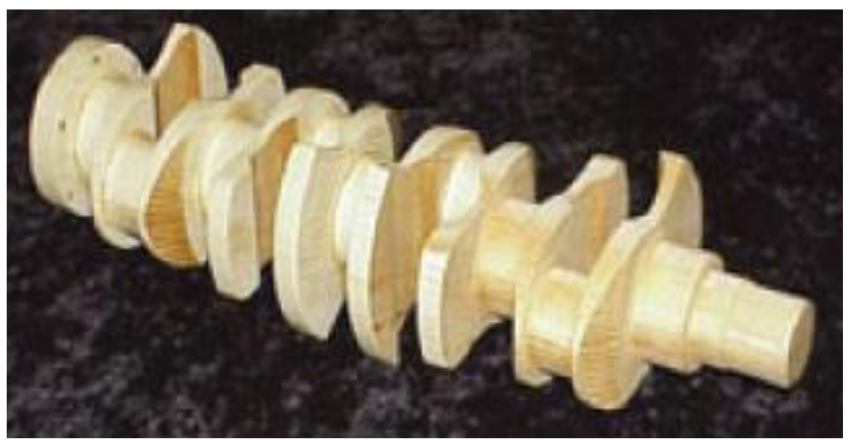

Fig. 5. Element (casting core) made by the LOM method [17]

This short description of the LOM process shows how impressive its scope of application is. In addition, each glued layer is a 1D microelement - that is, according to the definitions formulated at the beginning, the advanced additive microtechnology. But can microdetails be manufactured by this method?

Yes, first of all, 1D microelements not exceeding $1 \mathrm{~mm}$ thick, formed as a result of gluing layers of thickness, e.g. hundredths of a millimeter. A suitable laser cutting system also allows the production of 2D and 3D microelements.

\section{Selective laser sintering (SLS, SLM) of powders of any materials}

SLS is a process of connecting grains of powders of any materials as a result of phenomena occurring at grain boundaries (sintering, sintering with re-melting). Modern systems for the SLS process make it possible to obtain a sintered (or fused) layer with a minimum thickness of a few to several micrometers, and as shown in fig. 6, each layer is made of 2D microelements.

Powders of metals, alloys, ceramics and plastics, e.g. polyamides (PA), polystyrene (PS) or polycarbonates (PC) can be used in the SLS process. Sintering of metals is carried out in an atmosphere without oxygen or air (in nitrogen, argon, vacuum). Commonly used materials are: molybdenum, tungsten, silver, stainless steel and ceramics (Al203 - Si02). Powder grains range from nanometers to tens of micrometers. 
Lasers with a power of up to $20 \mathrm{~W}$ and a spot diameter of about $20 \mu \mathrm{m}$ are used for sintering. Layers 1 to 5 $\mu \mathrm{m}$ thick can be achieved; the minimum thickness of obtained walls is $30 \mu \mathrm{m}$ [16]. Because the object is built of microelements (1D or 2D), SLS or SLM processes allow the production of micro-, meso and macroelements. Based on the definitions presented at the beginning, SLS and SLM processes can be classified as microtechnology.

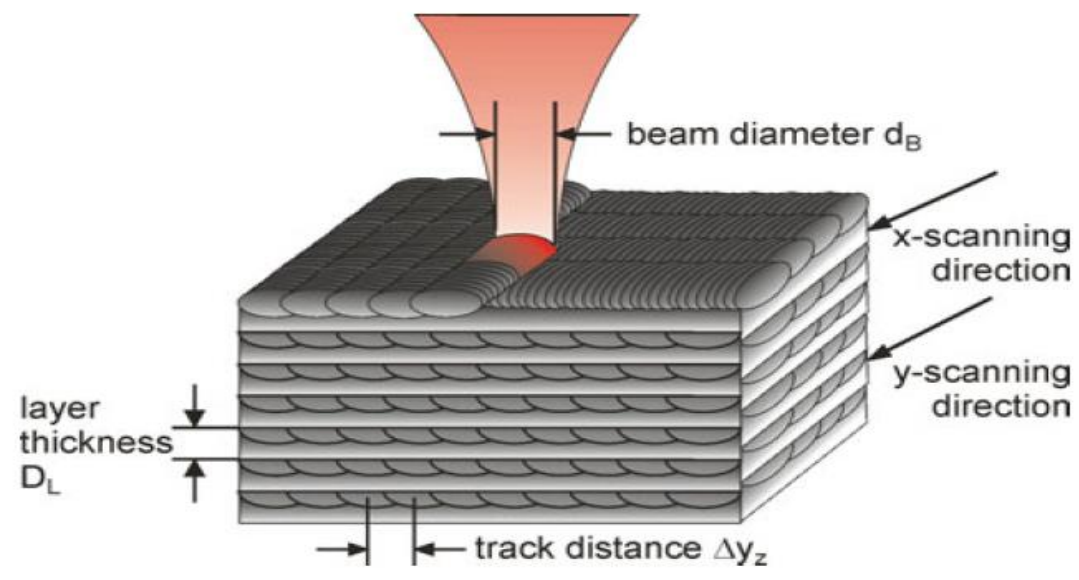

Fig. 6. SLS powders process diagram [17]

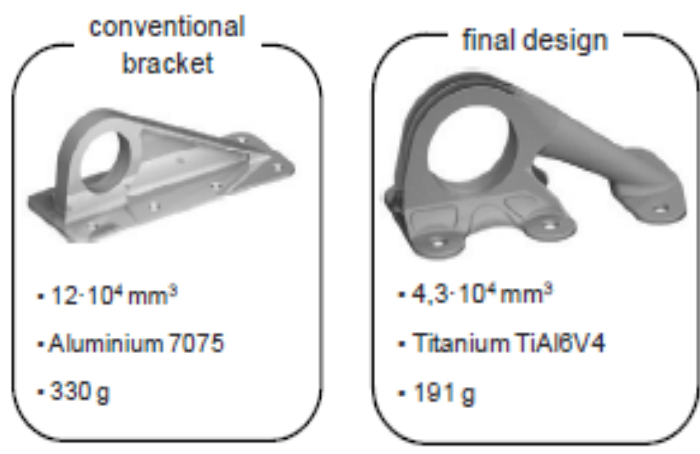

Fig. 7. Examples of brake bodies: conventional and bionic. The shape of the bionic body can only be obtained by additive methods [18]

\section{Stereolithography (SL)}

In stereolithography, the phenomenon of photopolymerization (change of liquid state to solid) of a thin layer of liquid monomer under the influence of ultraviolet light of the appropriate wavelength, usually emitted by a laser, is used. The thickness of the applied layer under micro-manufacturing conditions is $1 \div 20 \mu \mathrm{m}$, and in the two-photon polymerization process (2pp) the added 3D elements can have a minimum dimension of $100 \div 200$ $\mathrm{nm}$, i.e. they reach the nanotechnology dimensional limits $[7,16,21]$.

In classical stereolithography, the thickness of the layer is determined by choosing the average irradiation time for a given type of photo-initiator and its concentration. The longer the exposure time, the thicker the layer formed. An example of the use of classical stereolithography in the production of bionic elements is shown in fig. 8.

The starting materials for stereolithography production may be: acrylic acid, methacrylic acid and their derivatives (such as nitriles, amides and esters), epoxy resins and vinyl resins.

The two-photon polymerization process (2pp) was developed by Maruo and Kawat in order to remove restrictions on the resolution of structures created in the micro-SL process $[7,16,17,20]$. Femtosecond lasers are required for its implementation. An energy pulse from such a laser is enough to produce the photon density required for polymerization. In the $2 \mathrm{pp}$ process, a photo-initiator needs two photons to initiate photopolymerization. The laser power should be selected so that the limiting power necessary to initiate photopolymerization is exceeded only in the center of the laser spot. Thanks to this - although the dimensions of the laser light spot are on the order of micrometers - the area of polymerization that occurs can be much smaller, which up to ten 
times improves the resolution of created structures compared to classical stereolithography. The use of femtosecond laser allows to obtain spatial dimensional resolution in the range of $100 \div 200 \mathrm{~nm}$. The $2 \mathrm{pp}$ process finds application in the production of micro-rotors, micro-oscillators, photonic crystals and optical memories.

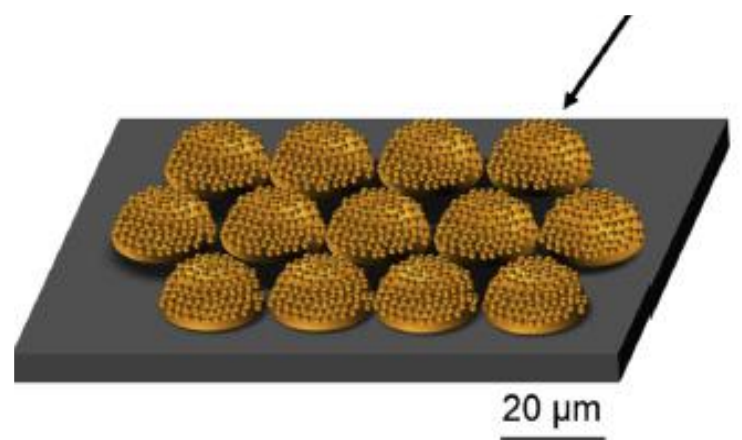

Fig. 8. Optical element in the shape of an enlarged mosquito eye. There are many almost spherical shapes (hemispherical forms) on the surface that generate such functions as: hydrophobicity, anti-reflection, resistance to dirt [19]

a)

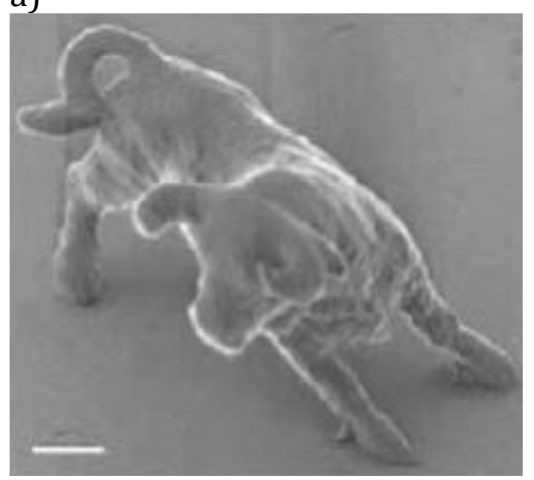

b)

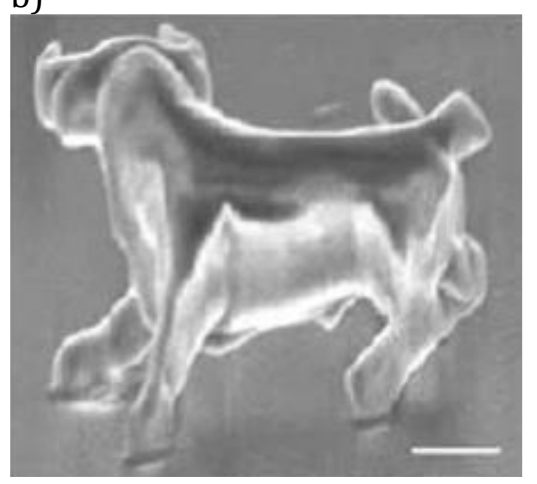

Fig. 9. Bull models made in the $2 p p$ process. The segment in the drawing has a dimension of $1 \mu \mathrm{m}$ [16]

Nanoscribe Company GmbH has developed a commercial 3D lithography system based on 2pp polymerization: Photonic Professional GT. The system performs 3D micro printing and maskless lithography with a resolution of approx. $100 \div 200 \mathrm{~nm}[23]$.

\section{Process fused deposition modelling (FDM)}

In this method, the plastic fiber is plasticized in a special nozzle and applied to create the surface of the shaped element (fig. 10). The FDM method has found wide application in the production of experimental models and prototypes during the design of various devices.

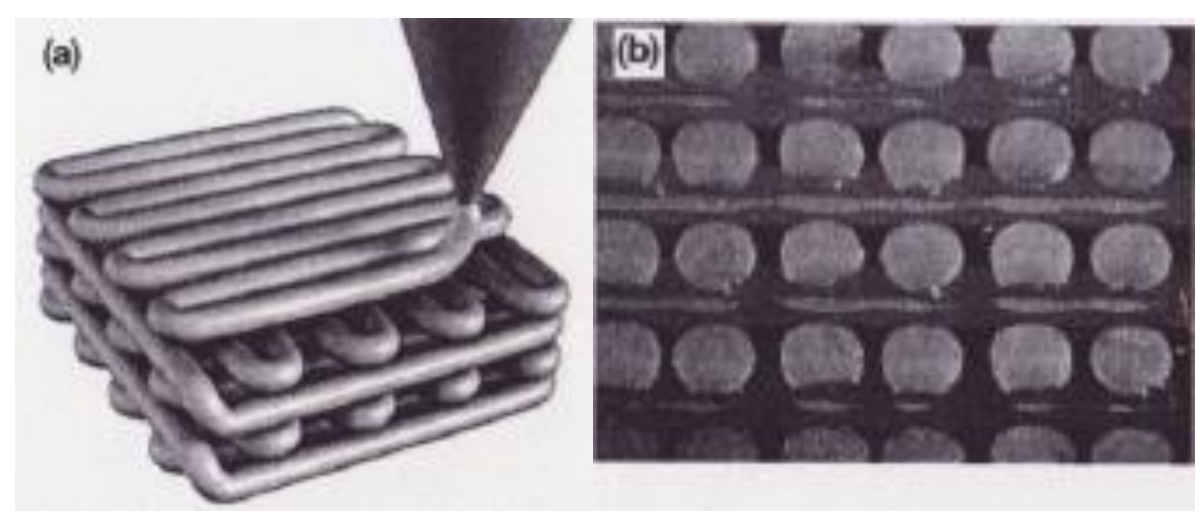

Fig. 10. Diagram of object formation by adding plasticized fibers (2D microelements) - FDM process (a) and cross-section of the microstructure of a part made using the FDM method $(b)[7,17]$ 
FDM is increasingly used in biomedical engineering for the production of all kinds of prostheses (in orthopedics and dentistry], tissue models and prototypes and elements of special equipment, e.g. for the supply and distribution of medicines [7].

\section{$3 D$ printing $(3 D P)$}

Building elements by applying material drop by drop is carried out with at least two nozzles: one is for applying the material of the object, and the other - for applying the support material. The nozzles dispense drop by drop the applied material, and the drop is usually a microelement (3D) $[7,16]$. The principle of this process is explained in fig. 11.

The process enables building microelements from layers with a thickness of $16 \mu \mathrm{m}$, with a resolution of 42 $\mu \mathrm{m}$. It is used in the production of jewellery, medical parts (e.g. elements of hearing aids), robotic surgical technologies such as endoscopy or laparoscopy (filling material shortages in tissues, internal organs, etc.) and in dentistry (e.g. production of teeth) [7].

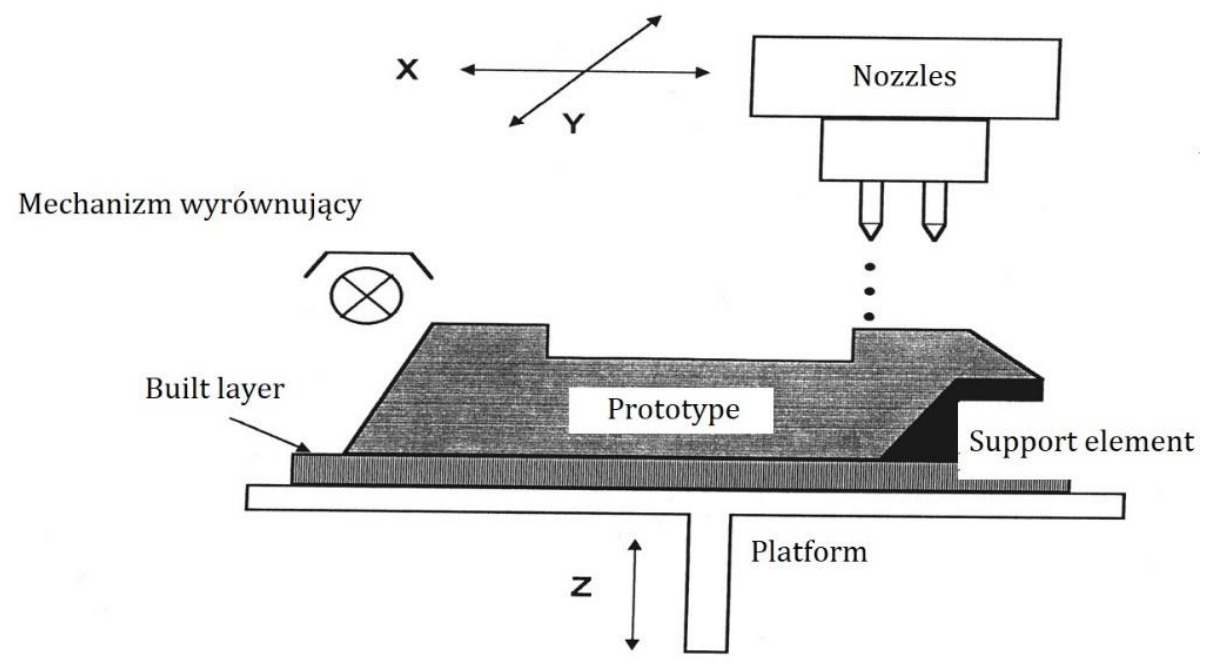

Fig. 11. Diagram explaining the principle of building a model by adding drops of material - each drop is a $3 \mathrm{D}$ microelement $[7,16,17,21]$

An interesting variation of 3D printing is building an element by joining powders with binder drops $[7,16$, 22]. The powder layer is prepared in the same way as in the SLS process, and then the binder is added drop by drop in places where the grains are to be joined [7, 22]. The element shaped in this way can be subjected to further heat treatment (fig. 12).

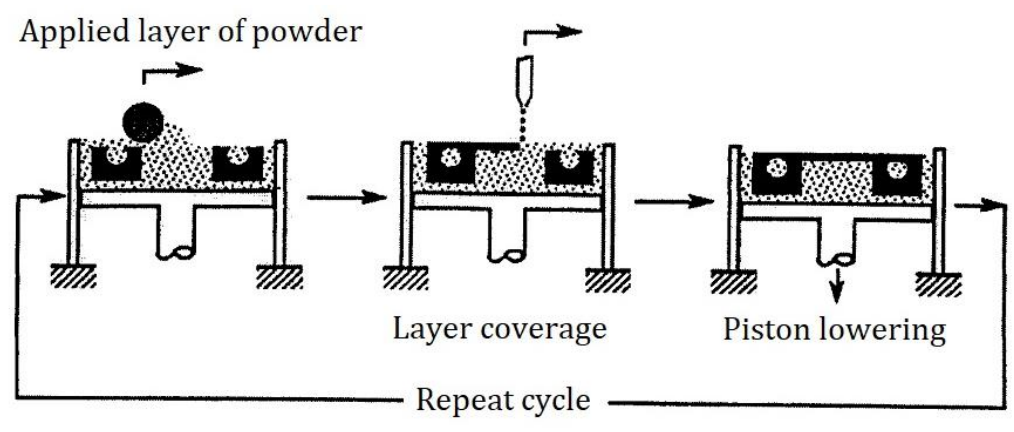

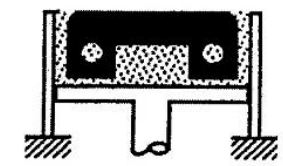

Intermediate stadium

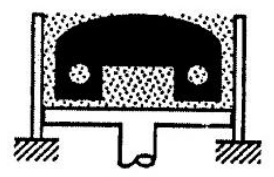

Apply last layer

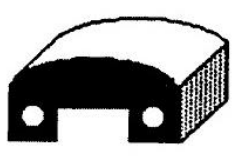

Made item

Fig. 12. Principle of producing elements by bonding powder grains with glue drops [23]; minimum powder layer thickness $\sim 45 \mu \mathrm{m}$ 
The process allows to build elements with complex internal structures (with empty interiors or with spaces filled with light materials). This method allows to reduce the mass of elements, which is of particular importance in the aerospace industry. In addition, the relatively high resolution and the fact that after sintering the element can be polished $(R a<1 \mu \mathrm{m})$, expand the possibilities of using this method in dentistry and medicine and jewellery $[7,16,22]$.

\section{Summary}

The definitions of nano- and microtechnology introduced at the beginning are closely related to the results of research on processes occurring in nature. Therefore, since the 1960 s we have been observing the parallel development of micro- and nanotechnology and bionics. It is worth emphasizing that the development processes of living organisms in nature are incremental nanotechnologies that provide extraordinary efficiency and diversity of emerging organisms.

Based on the observation of the development of incremental manufacturing techniques, it can be stated that their share in production processes is growing dynamically. The considerations presented in the paper also show that in such processes as LOM, SLS, SLA, FDM or 3DP, elements (meso or macro) are built of microelements (1D, 2D or 3D $\ll 1 \mathrm{~mm}$ ), thus they are commonly used in the microtechnology industry.

\section{REFERENCES}

[1] Feynman R.P. “There's plenty of room at the bottom”. Engineering and Science. 23, 5 (1960): 22-36.

[2] Samek A. „Bionika. Wiedza przyrodnicza dla inżynierów”. Kraków: Wydawnictwa AGH, 2010.

[3] Ruszaj A., Skoczypiec S., Wyszyński D., Lipiec P. „Wybrane aspekty zastosowania mikro- i nanotechnologii w procesach wytwarzania". Inżynieria Maszyn. 4 (2011): 7-18.

[4] Węgrzyn S. Znamirowski L. „Zarys nanonauki i informatycznych molekularnych nanotechnologii”. Gliwice: Wydawnictwo Politechniki Śląskiej, 2008.

[5] Brinksmeier E., Mutlugunes Y., Klocke F, et al. "Ultra-Precision Grinding”. Cirp Annals - Manufacturing Technology. 59 (2010): 652-671.

[6] Dornfeld D., Min S., Takeuchi Y. "Recent Advances in Mechanical Micromachining”. Cirp Annals - Manufacturing Technology. 55, 2 (2006): 745-768.

[7] Fassi I., Shipley D. "Micro-manufacturing Technologies and Their Applications; A theoretical and Practical Guide". Springer International Publishing: Switzerland, 2017.

[8] Shashi P., Subrata K. "Experimental investigations and analytical model of multi-pass $\mathrm{CO}_{2}$ laser processing on PMMA". Precision Engineering. 49 (2017): 220-234, DOI: https://doi.org/10.1016/i.precisioneng.2017.02.010.

[9] Fiorucci M.P., Lopez A.J., Ramil A. "Multi-scale characterization on topographic modification on metallic biomaterial induced by nanosecond Nd:YVO 4 laser structuring". Precision Engineering. 5 (2018): 163168, DOI: https://doi.org/10.1016/i.precisioneng.2018.03.009.

[10] Koyano T., Kunieda M. "Ultra-short pulse ECM Rusing electrostatic induction feeding method". Procedia CIRP. 6 (2013): 390-384, DOI: https://doi.org/10.1016/j.procir.2013.03.066.

[11] Ruszaj A., Cygnar M., Grabowski M. "The State of the Art in Electrochemical Machining Process Modeling and Applications". AIP Conference Proceedings 2017. 020029 (2018), DOI: https://doi.org/10.1063/1.5056292.

[12] Dong X., Chen F., Chen S., Yang Liu, et al. "Microstructure and microhardness of hot Extruded 7075 aluminium alloy micro gear". Journal of Materials Processing Technology. 219 (2015): 199-208, DOI: https://doi.org/10.1016/i.jmatprotec.2014.12.022.

[13] Su Yo-C, Shah J., Lin L. "Implementation and analysis of polymeric microstructures replication by micro-injection molding". J Micromech Microengineering. 14 (2014): 415-422.

[14] Oczoś K.E. „Rosnące znaczenie Rapid Manufacturing w przyrostowym kształtowaniu wyrobów”. Mechanik. 4 (2008): 241-247.

[15] Thompson M.K., et al. "Design for Additive Manufacturing: Trends, opportunities, considerations and constraints". CIRP Annals - Manufacturing Technology. 65 (2016): 737-760, DOI: https://doi.org/10.1016/i.cirp.2016.05.004. 
[16] Gibson I., Rosen D.W., Stucker B. “Additive Manufacturing Technologies: Rapid Prototyping to Direct Digital Manufacturing". Springer Science + Busines Media, 2010.

[17] Poprawe R. "Tailored Light 2. Laser Application Technology". Springer, 2011.

[18] Emmelmann C., Sander P., Kranz J., Wycisk E. "Laser additive manufacturing and bionic: Redefining lightweight design". Physics Procedia. 12 (2011): 364-368, DOI: https://doi.org/10.1016/i.phpro.2011.03.046.

[19] Suzuki Y., Suzuki K., Michihata M., Takamasu K., Takahashi S. “One-shot stereolithography for biomimetic micro hemisphere covered with relief structure". Precision Engineering. 54 (2018): 353-360, DOI: https://doi.org/10.1016/i.precisioneng.2018.07.004.

[20] Wrzyszczyński A. „Dwufotonowe inicjatory polimeryzacji”. Polimery. 3, LV (2010): 167-171.

[21] Gatto A., Iuliano L., Settineri L. "Particles' formation and deposition in the sanders RP process". Proceedings of the 7th European Conference on Rapid Prototyping and Manufacturing. Aachen, Germany: AGIT Technology Centre (1998): 211-226.

[22] Jee H. J., Sachs E. "Visually simulated surface texture models for 3D printing". Proceedings of the 7th Conference on Rapid Prototyping and Manufacturing. Aachen, Germany: AGIT Technology Centre (1998): 49-62.

[23] www.nanosribe.com. 